Resumen por el autor, Frank Blair Hanson.

Universidad Washington, Saint Louis.

El desarrollo de la cintura escapular de Sus scrofa.

En el cerdo la cintura escapular está reducida a su mas mínima expresión, consistiendo simplemente de dos piezas, la escápula y el subcoracoides. Las clavículas, acromion y el proceso coracoides están completamente reducidos. La cintura escapular de este animal es además una estructura primitiva que lleva una supra-escápula de gran tamaño y estructura cartilaginosa permanente. La escápula probablemente no es una estructura segmentaria y el subcoracoides puede ser simplemente una epífisis.

Translation by José F. Nonidez

Carnegic Institution of Washington 


\title{
THE DEVELOPMENT OF THE SHOULDER-GIRDLE OF SUS SCROFA
}

\author{
FRANK BLAIR HANSON \\ Department of Zoology, Washington University, St. Louis, Missouri \\ SEVEN PLATES (TWENTY-EIGHT FIGURES)
}

\section{INTRODUCTION}

It was the idea of Mall, and also of His, that an embryological study should be carried to its logical conclusion, i.e., followed on through the stages of organogenesis and to adult life. Development is a life-long process, and an investigation can only approximate completeness which takes into account this fact. This paper in a most modest way is an attempted illustration of this principle.

In order to compress the material as compactly as possible, the body of the article contains only a discussion of the more general features of the pig scapula, while the anatomical details of each stage are briefly stated in the explanation of figures 1 to 28 .

One of the admitted difficulties of following an embryological investigation into fetal and postnatal life is often the scarcity or inaccessibility of the material. In this present instance I am greatly indebted to Mr. A. J. Green, superintendent of the Swift Packing Company plant in St. Louis, for the series of fetal and postnatal scapulae used in this investigation. The drawings were made by Miss Bertha Uhlemeyer, whose aid makes possible the appearance of the paper at this time.

\section{GENERAL DISCUSSION}

There is neither an account nor figures of the pig scapula to be found in the literature, so far as I am aware. Yet in several respects this bone is unique among mammalian scapulae. In the pig the shoulder-girdle is reduced to its lowest terms, con- 
sisting simply of two pieces, the scapula and the subcoracoid, glenoid sharing element. Clavicles, acromian, and coracoid process are completely aborted, indicating the maximum amount of degeneration possible with continued functional efficiency. The loss of the clavicles is naturally followed by the disappearance of the acromian, except as it may occur in a rudimentary nodule of bone at the lower end of the spine (fig. 23).

The disappearance of the coracoid process may be accounted for as follows: Broom ('97, '98, '99, '02) found that in all groups of marsupials the embryos and fetuses had a coracoidal bar extending from the acromial process of the scapula to the anterolateral margin of the sternum. As development proceeds, degeneration sets in at the middle of this coracoidal bar and, proceeding in each direction, causes the complete disappearance of the sternal half of the coracoid. In the scapular half of the coracoid degeneration is incomplete, leaving attached to the scapula the well-known coracoid process of the adult marsupial. It is highly probable that this is the explanation of the presence of the coracoid process in all groups of mammals. Paterson ('00, '02, '04) found in the rat a mesenchymatous coracoidal bar extending from the mesenchymatous anlage of the scapula to the fundament of the presternum. Here also degeneration in an early stage removes this coracoid, but, unlike the marsupial, not only is a coracoid process left attached to the scapula, but the sternal half is represented here also by a coracoid process attached to the sternum. This persists into adult life as a little nodule of bone lying between the clavicle and first rib, and is called by Parker ('68) the epicoracoid.

In the pig a third variation of this process is illustrated, for here the degeneration is complete in both the sternal and scapular halves of the coracoid, leaving no trace of its embryonic existence either on sternum or scapula. I have verified Paterson's account of the presence of a complete mesenchymatous coracoid in the rat, mouse, cat, and human embryos. Watson ('17) has checked up Broom's work on the marsupials. It is, therefore, well established for a few representative mammals, and is probably true for all; that such an embryonic coracoid does occur, 
the only evidence of its existence in the adult being the wellknown and much-discussed coracoid process.

The subcoracoid (fig. 27), which in the pig occupies roughly one-third of the area of the glenoid surface, I have discussed elsewhere (Hanson, '19). Suffice to say here that its homologies are still in uncertainty; it may be merely an epiphysis such as occurs on long bones, as suggested by Broom and Gregory ('18). The subcoracoid is ossified from a separate center which does not appear until some months after birth. There is but one other center of ossification in the shoulder-girdle of the pig, that of the blade part of the scapula.

Not only is the scapula highly degenerate, but it also shows an unmistakable primitiveness in the possession of a large and permanent suprascapula. By reference to the figures it will be seen that in the oldest scapulae the suprascapula retains the same relative proportions to the scapula as in the fetal scapulae. There is no evidence of even the beginning of ossification in the scapula of a boar (fig. 28) which weighed 450 pounds and was evidently of considerable age. In most mammals advancing age brings an ossification and reduction in size of the embryonic suprascapula, to which rule the pig appears to be an exception. I have shown (Hanson, '18) that in a phylogenetic ascending series of mammalian scapulae the progressive diminution of the suprascapulae follows closely the steps of ontogenetic development in the highest order of mammals. The permanent suprascapula of the pig recalls conditions in the Amphibia and Reptilia.

The pig has a scapular index ranging from 137 to 150 , these measurements, however, are based on only a dozen blade bones. The scapular index of any animal is obtained by multiplying the length from the glenoid to the vertebral border by 100 , and dividing this by the distance from the medial to the inferior angle. It is interesting in this connection to note that the cat has a scapular index of 200 , while that of man averages only 65 for the white races.

Kingsley ('00) has suggested that the presence of nerves and their foramina in the suprascapula might possibly indicate that the scapula was made up of metameric parts. Bolk's studies of 
the muscles of the shoulder-girdle, together with the fact that when the suprascapula ossifies, as in man, it is by a series of ossific centers, which might indicate previously existing, separate, metameric bones, lend support to this theory, as does also the generally constant division of the scapula in mammals into a prescapula, mesoscapula, and postscapula. However, since the presence of the nerves in the suprascapula is merely a secondary association, as shown by Hanson ('19 b), and, further, when it is considered that the mammalian scapula is the undoubted homologue of the cartilaginous scapula of the dogfish, which is a simple bar of cartilage, that could in no way possible be related to metamerism, it seems impossible to accept the theory of a metameric origin for the scapula.

Attention is called to figures $14,15,24$, and 25 , which are of wild pigs from Honduras, the Celebes, and Borneo. The scapulae are essentially like those of Sus scrofa, but are much narrower and stand higher on the animal's body than in the domestic pig. Nerve foramina are present, while acromian and coracoid process are lacking.

As will be seen by the figures, the suprascapula, both fetal and adult, contains a varying number of nerve foramina. Hanson ('19 b) has given an account of this peculiarity, and believes it to be limited to the family Suidae among living mammals. Since the publication of my paper on this subject, Dr. R. L. Moodie has called my attention to a fossil scapula of Trachodon annectens containing what might be interpreted as a nerve foramen. This scapula is described by Beecher ${ }^{1}$ as follows:

The right scapula is well preserved and shows one very interesting feature. Near the lower edge of the blade is an elongate elliptical hole. $8 \mathrm{~cm}$. in length, with smooth edges, indicating that the animal received a severe injury during life and completely recovered from it before death. It is, of course, idle to speculate on the character of this accident, yet the presence in the same beds of numerous remains of the armored and horned Triceratops suggest that there may have been an encounter between this Claosaurus and one of the individuals of the Ceratopsidae. The injury to the scapula is just such a one as could be made by a thrust of one of the horns of Triceratops.

1 Trans. Conn. Acad. Arts and Sc., 1902, vol. 11, p. 322, pl. 44, fig. 1. 
Thus Beecher regards this opening as pathologic or merely the result of an accident. Moodie, ${ }^{2}$ on the other hand, feels sure that Beecher is mistaken, and that we are here dealing with the nerve foramina of possibly aberrant spinal nerves. This latter contention is further corroborated by the presence of similar bony foramina in some of the dinosaurs, branchiosaurs, and cotylosaurs.

It is a matter of regret that at the present time the collection of fossils containing the Trachodon scapula is in storage and not available for reexamination.

\section{CONCLUSIONS}

From the foregoing account of the pig scapula, the following facts seem pertinent:

1. There is a permanent suprascapula, in which no centers of ossification ever appear.

2. There are in the entire shoulder-girdle only two ossific centers: one for the scapular blade and one for the subcoracoid.

3. Coracoid process, acromian, and clavicle are aborted.

4. The scapula is both primitive and degenerate.

5. The scapula is probably not a segmental structure.

: From a private communication to the author dated March 8, 1919. 


\section{LITERATURE CITED}

Вrоом, R. 1897 On the existence of a sternocoracoidal articulation in a fetal marsupial. Jour. of Anat. and Physiol., vol. 31. 1898 Description of the shoulder girdle in an $8.5 \mathrm{~mm}$. embryo of Trichosurus (not exact title). Proc. Linn. Soc. N.S.W., 1898. 1899 On the development and morphology of the marsupial shoulder girdle. Trans. Roy. Soc. Edinb., vol. 39, pt. 3, pp. 749-770. 1902 On the early condition of the shoulder girdle in the Polyprotodont marsupial Dasyurus and Perameles. Linn. Soc. Zool., vol. 28.

Gregory, W. K., AND CAMP, C. L. 1918 Studies in comparative myology and osteology. No. III. Bull. Am. Mus. Nat. Hist., vol. 38.

Hanson, Frank Blair 1918 The scapula of Tragulus. Anat. Rec., vol. 15, no. 4. 1919 a The coracoid of Sus serofa. Anat. Ree., vol. 16, no. 3. $1919 \mathrm{~b}$ Nerve foramina in the pig scapula. Anat. Rec., vol. 15, no. 6.

Kingstey, J. S. 1900 The foramina of the scapula. Science, N.S., vol.11, p. 167.

PArker, W. K. 1868 A monograph on the structure and development of the shoulder girdle and sternum in the vertebrata. Ray Soc. Lon.

Paterson, A. M. 1900 The sternum; its early development and ossification in inan and mammals. 1902 Development of the sternum and shoulder girdle in mammals. Brit. Med. Jour., vol. 2, p. 777. 1904 The human sternum. Liverpool.

Watson, D. M. S. 1917 The evolution of the tetrapod shoulder girdle and forelimb. Jour. of Anat., vol. 52, pt. 1. 


\section{PLATES}

ABBREVIATIONS

Ac, acromian

$\mathrm{Cr}$, coracoid

Sc, scapula

$G l$, glenoid

$S p$, spine

$S S c$, suprascapula

$\mathrm{Nf}$, nerve foramina 


\section{PLATE 1}

EXPLANATION OF FIGURES

1 Left scapula, 26-mm. embryo. Entirely cartilaginous. $\times 8$.

2 Right scapula of 33-mm. embryo. Center for ossification of blade has appeared, and occurs as a band of young bone cells occupying the upper part of the lower third of the scapula. $\times 7$.

3 Right scapula of $37-\mathrm{mm}$. pig, showing growth of bony part. Spine outlined in the cartilage and nerve foramina are present in the supraseapula. $\times 5$.

4 Left scapula of $47-\mathrm{mm}$. pig. $\times 5$.

5 Right blade bone of $72-\mathrm{mm}$. pig. $\times 4$.

6 Right blade bone of $77-\mathrm{mm}$. pig. Limits of future suprascapula outlined. Subcoracoid remains cartilaginous until after birth. $\times 4$.

7 Right scapula of $95-\mathrm{mm}$. pig. $\times 4$.

8 Right scapula of $107-\mathrm{mm}$. pig. $\times 3$. 
THF, SHOULDER-GIRDLE UF SUS SCROFA

PLATE 1 FRANK BLAIR HANBON
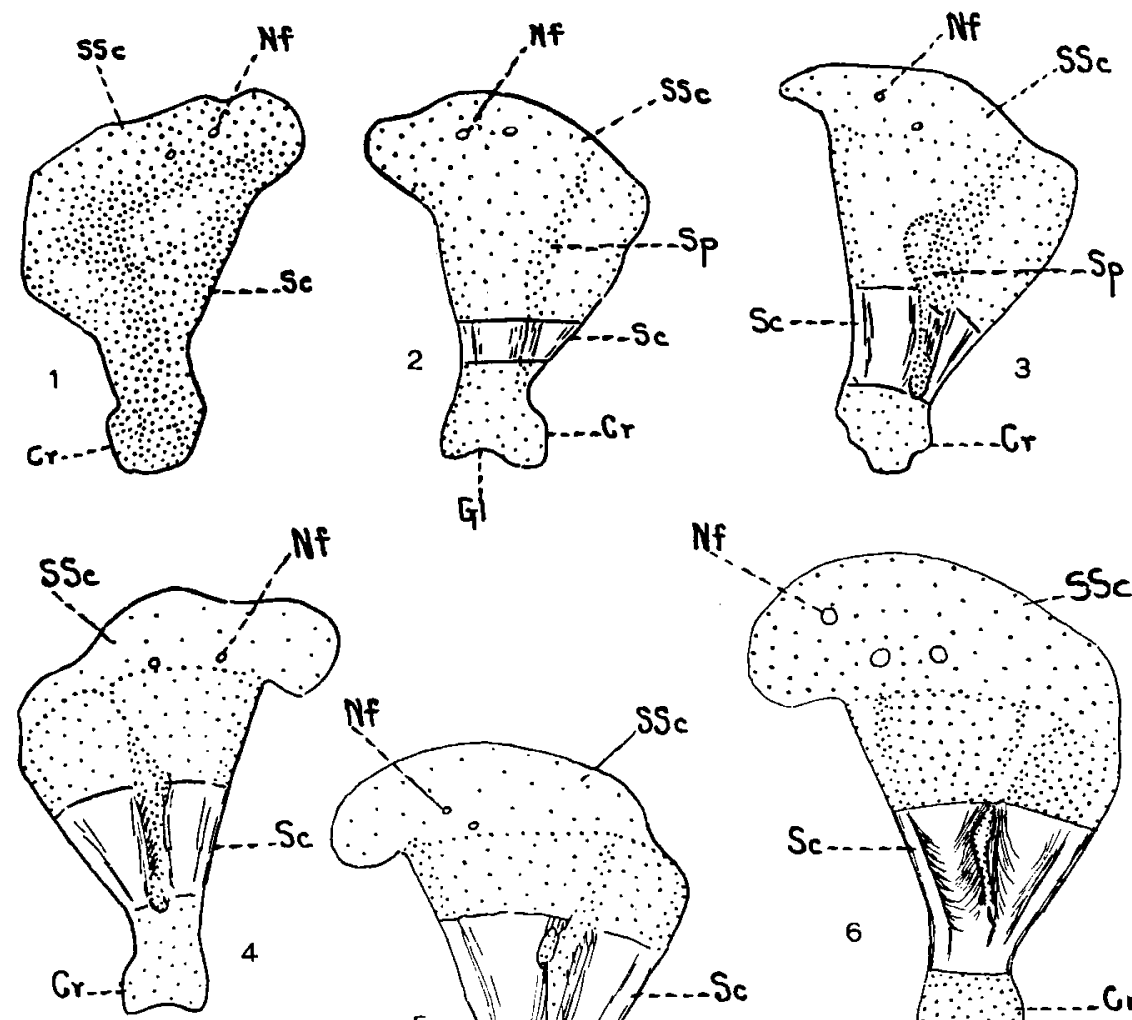

दो

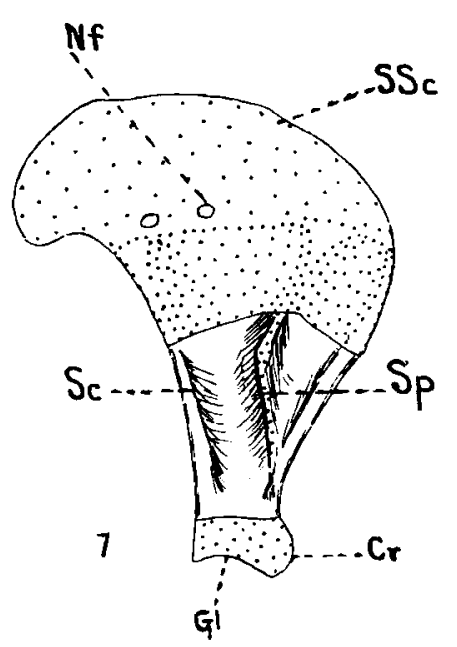

Nf
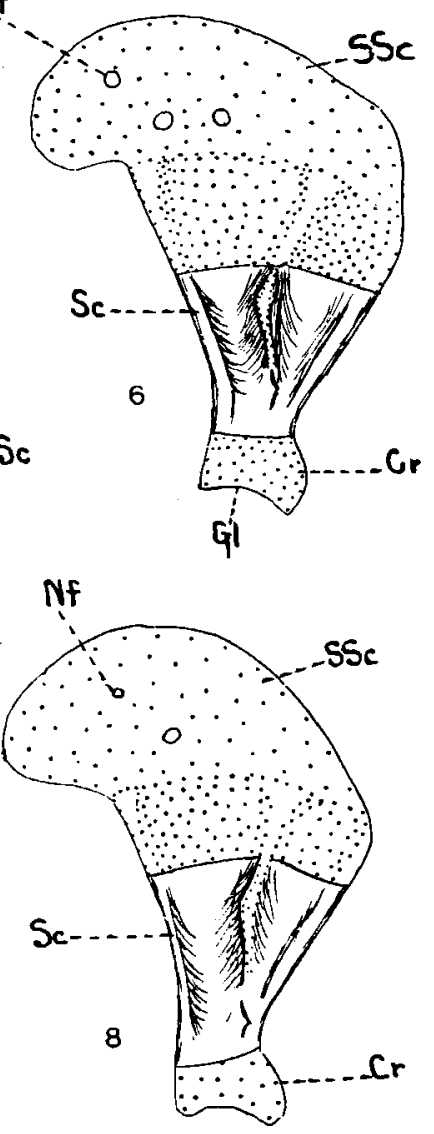
PLATE 2

EXPLANATION OF FIGURES

9 Right scapula of $131-\mathrm{mm}$. pig. $\times 2$.

10 Right scapula of $137-\mathrm{mm}$. pig. $\times 2$.

11 Right scapula of $150-\mathrm{mm}$. pig. $\times 1$.

12 Right scapula of $177-\mathrm{mm}$. pig. $\times 1$.

13 Right scapula of $200-\mathrm{mm}$. pig. $\times 1$. 

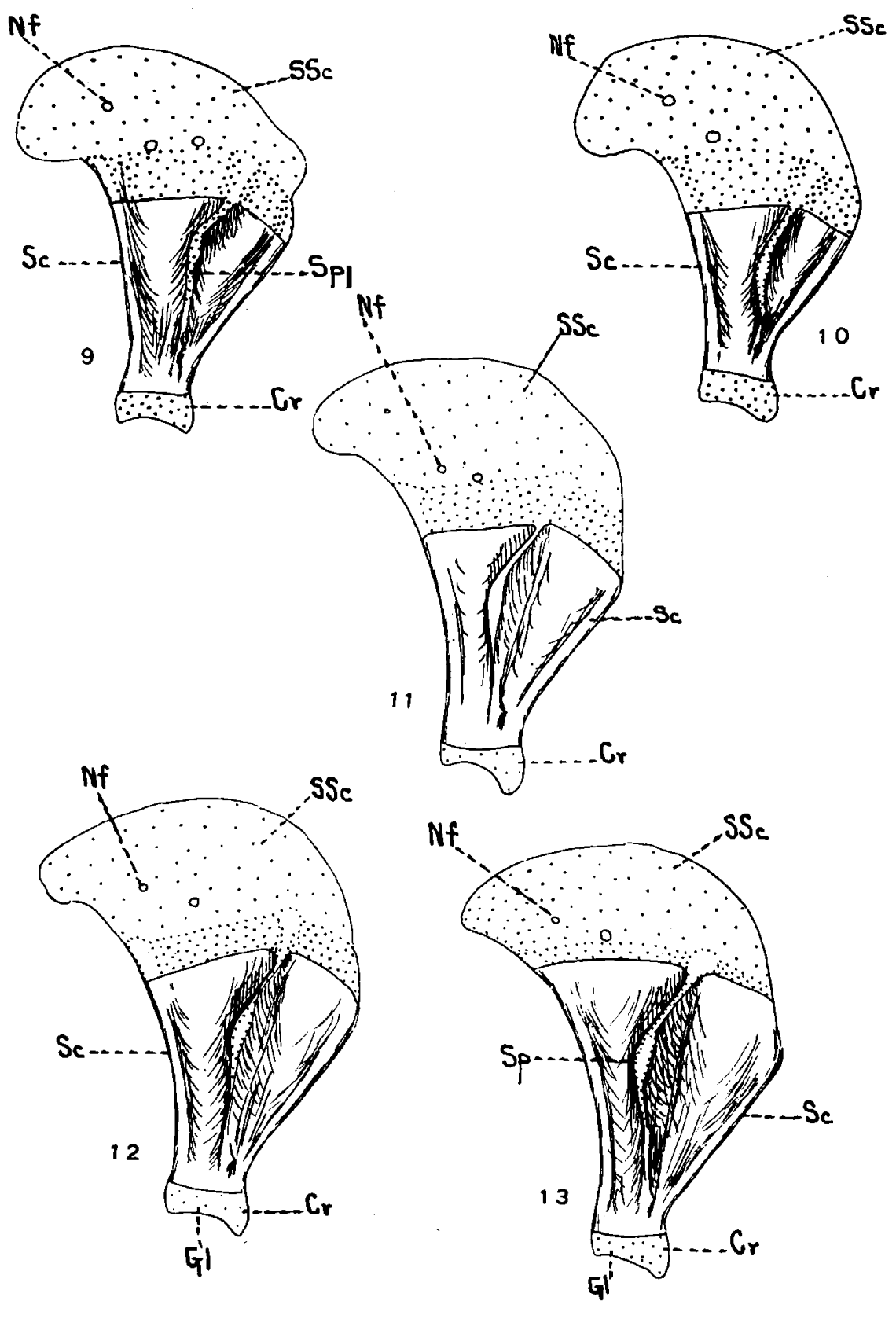


\section{PLATE 3}

\section{EXPLANATION OF FIGURES}

14 Right scapula of Sus barbatus fetus from Borneo. U. S. Nat. Mus. specimen, no. 5751. Bony scapula has now reached limits of its development, and is capped by what will be the permanent suprascapula.

15 Left scapula of Tayassu fetus from Honduras. U. S. Nat. Mus. specimen, no. 10214. Is peculiar in having only one nerve foramen.

16 and 17 Full term feti of domestic pig. Medial and lateral views. Adult shape of scapula has now been assumed. 
THE SHOULDER-GIRDLE OF SUS SCROFA

VRANK BI.AIR HANBON
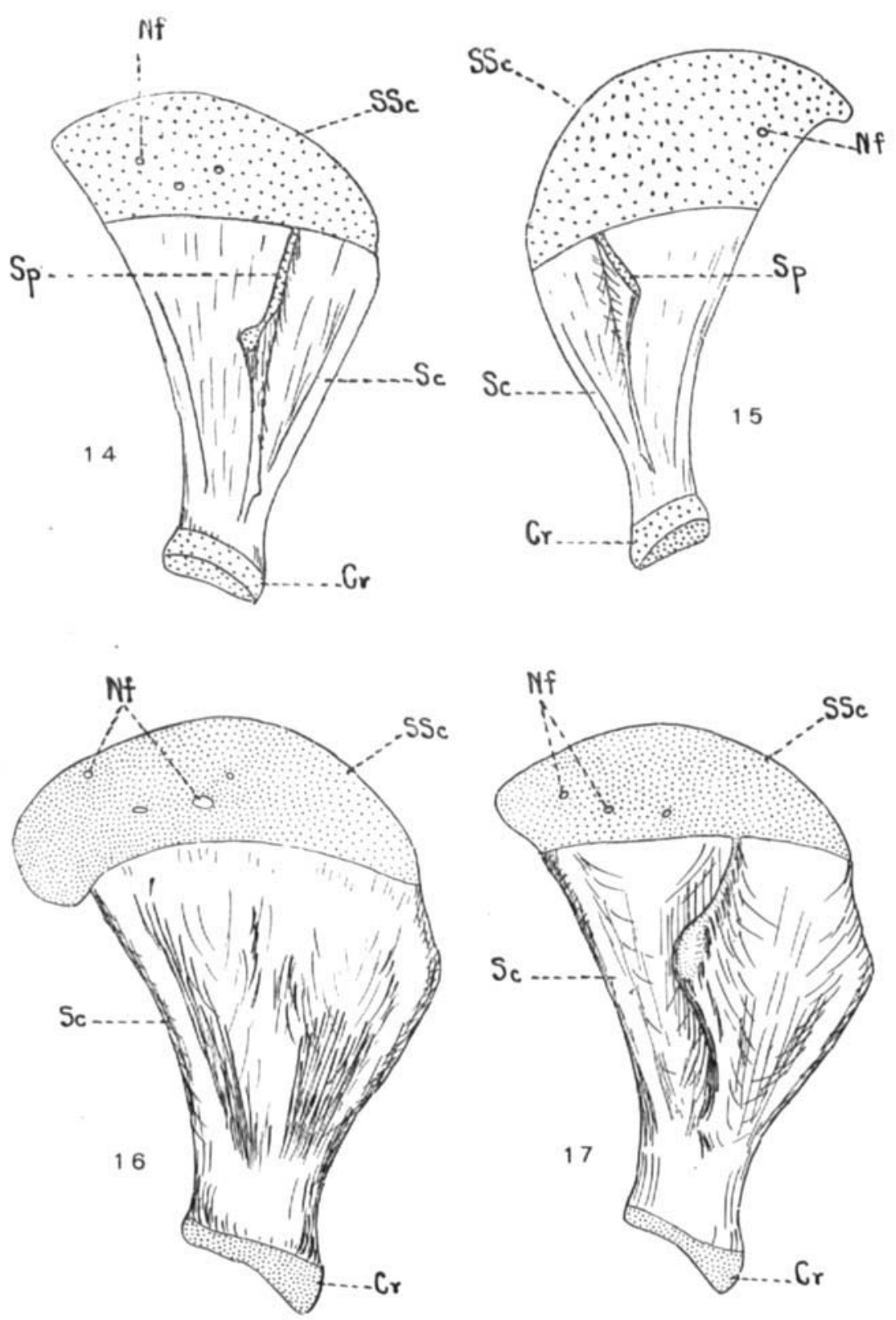


\section{PLATE 4}

EXPLANATION OF FIGURES

18 Lateral view of scapula of pig two weeks old. (1) length of scapula from glenoid to suprascapular border $50 \mathrm{~mm}$.; (2) length of bony scapula $40 \mathrm{~mm}$.; (3) width of suprascapula $10 \mathrm{~mm}$; (4) width of scapula through highest part of spine $23 \mathrm{~mm}$.; (5) height of spine $6 \mathrm{~mm}$. Note: Measurements of remaining scapulae will be given in same order as above and in millimeters.

19 Medial view of scapula of pig three weeks old. Measurements, $45 \times 37 \times 8 \times$ $13 \times 8$.

20 and 21 Lateral and medial views of pig approximately three months old. Measurements, $120 \times 98 \times 22 \times 60 \times 20$. Coracoid is still cartilaginous. 

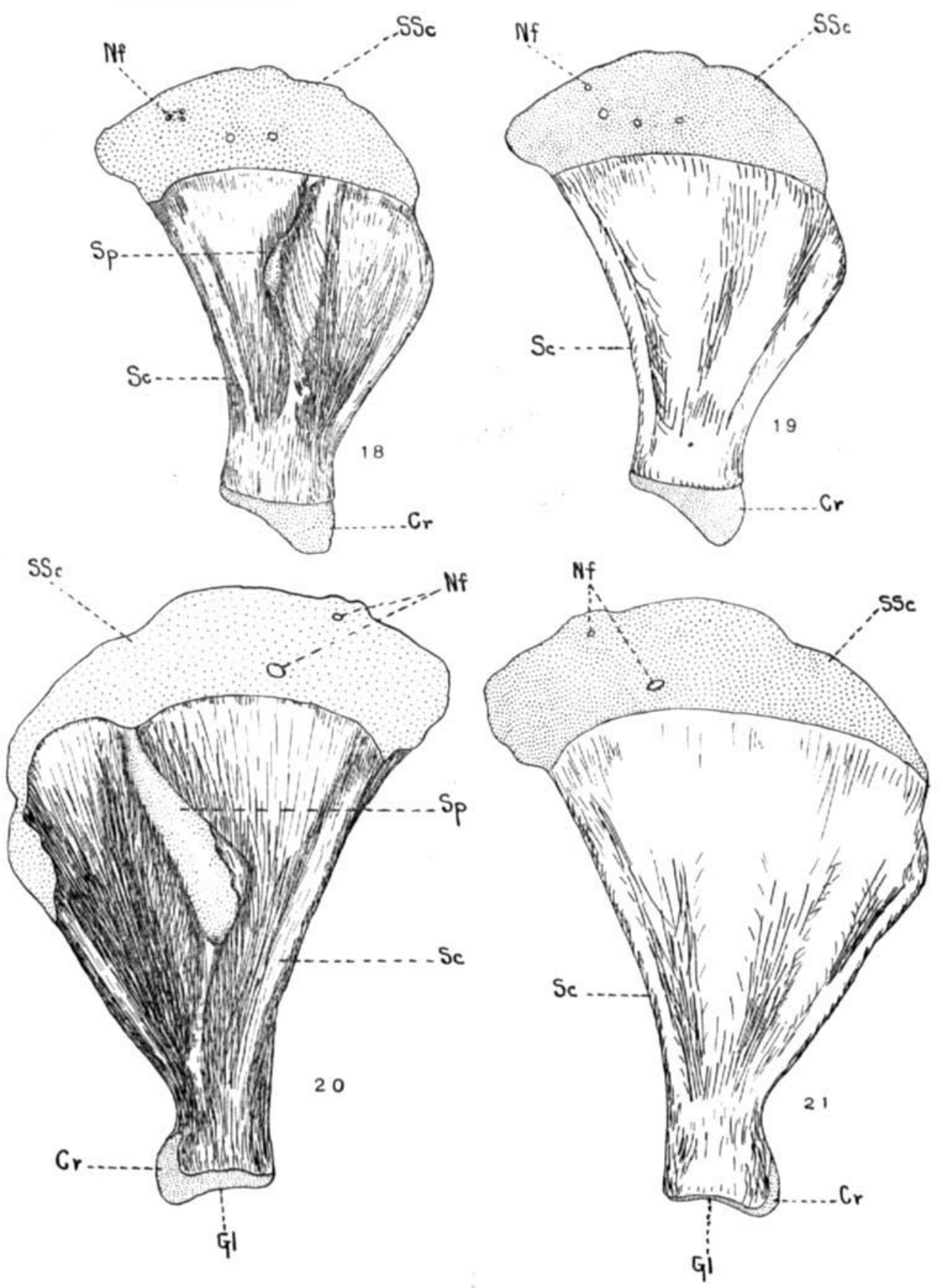


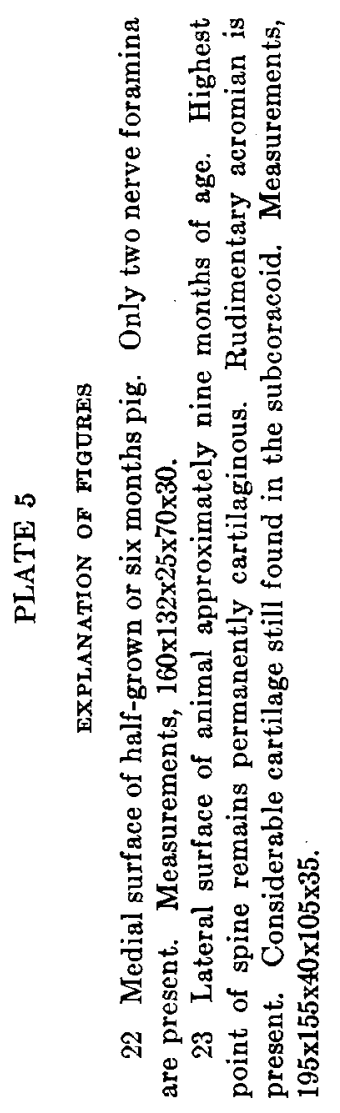



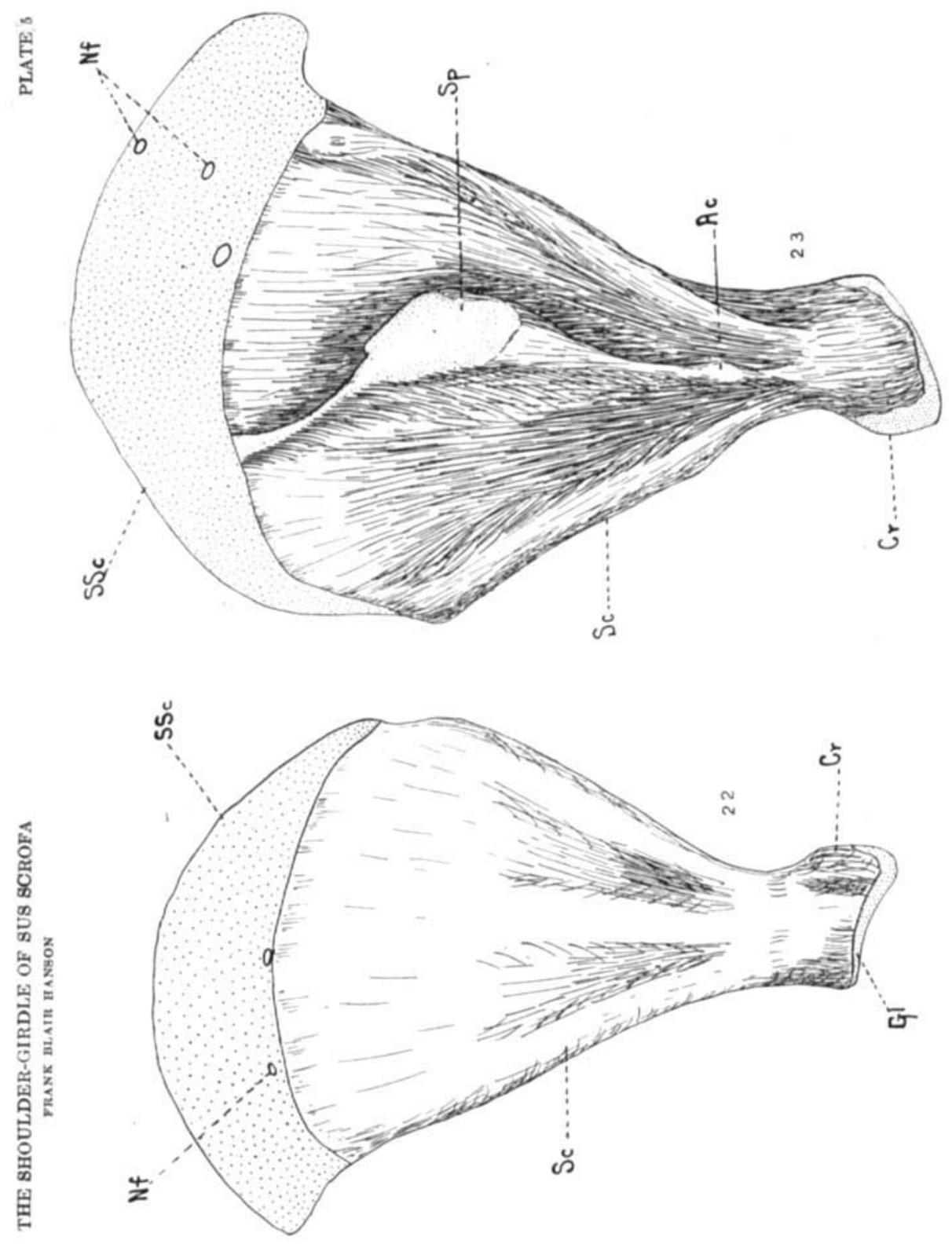


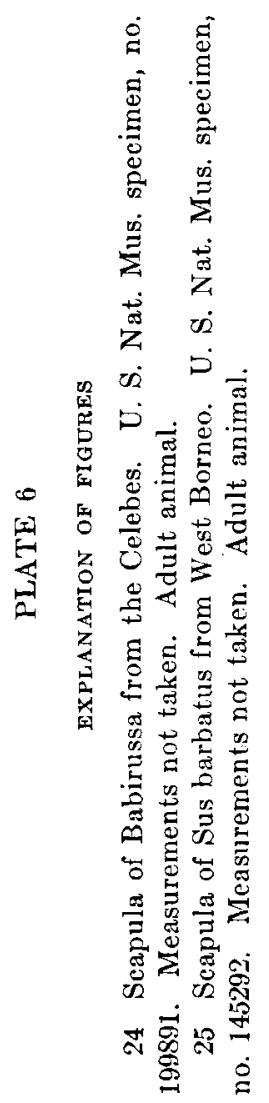




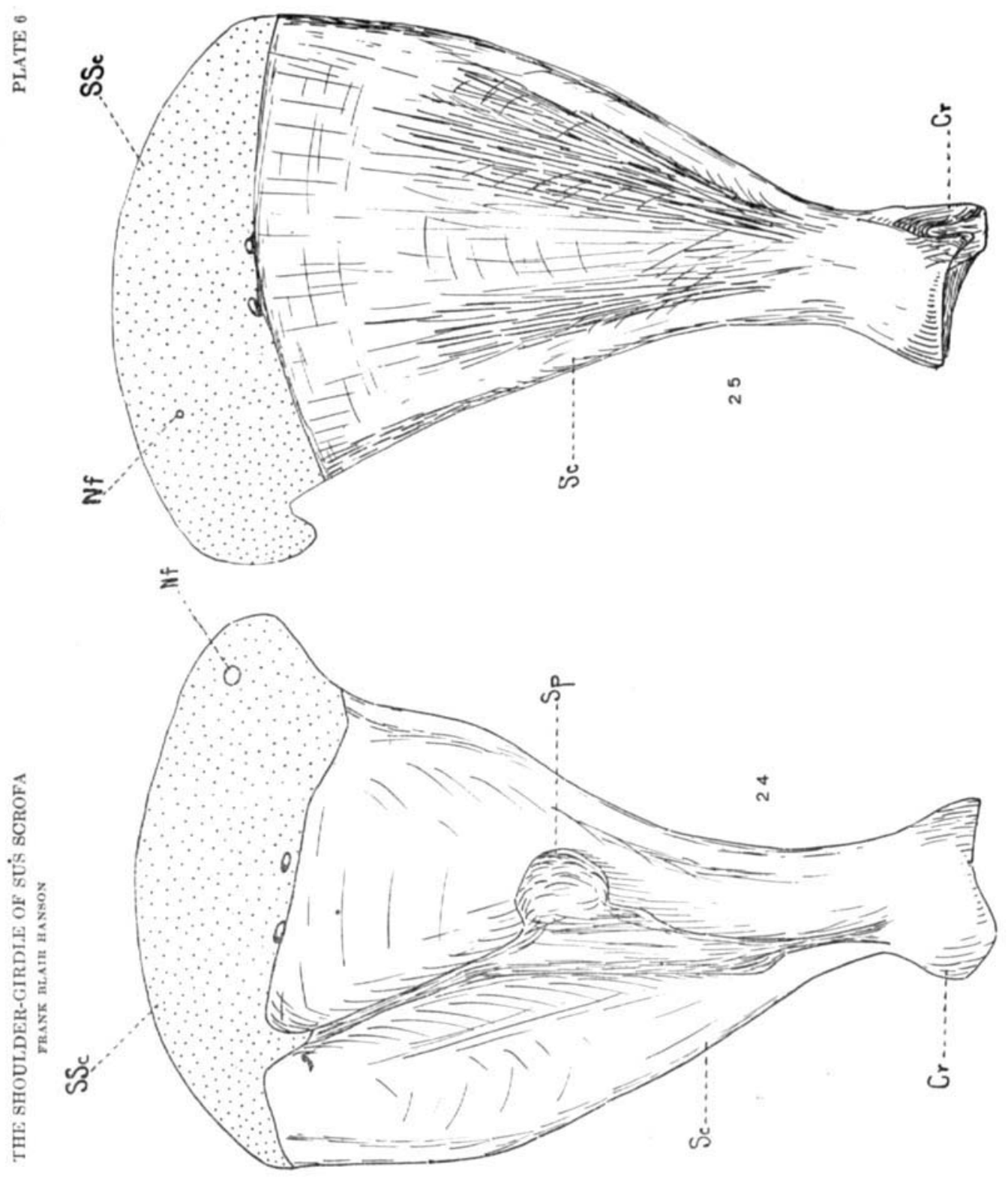

19 


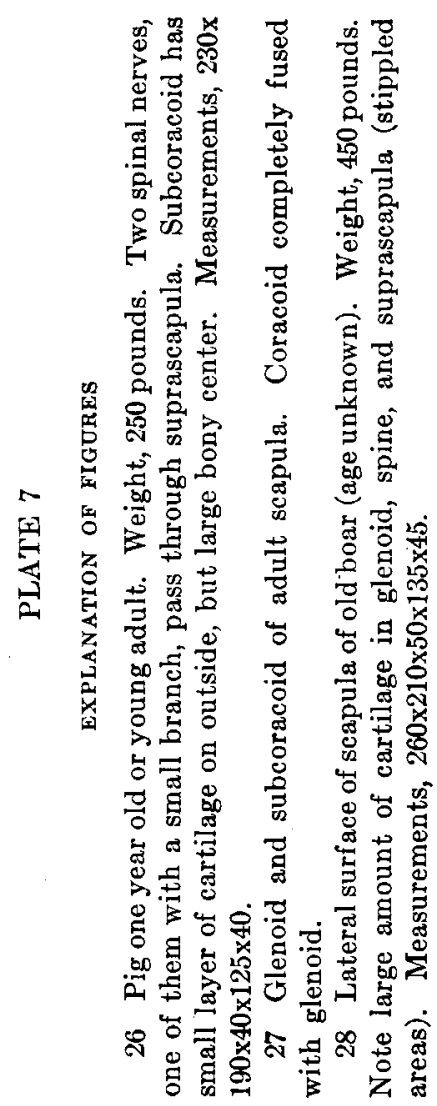




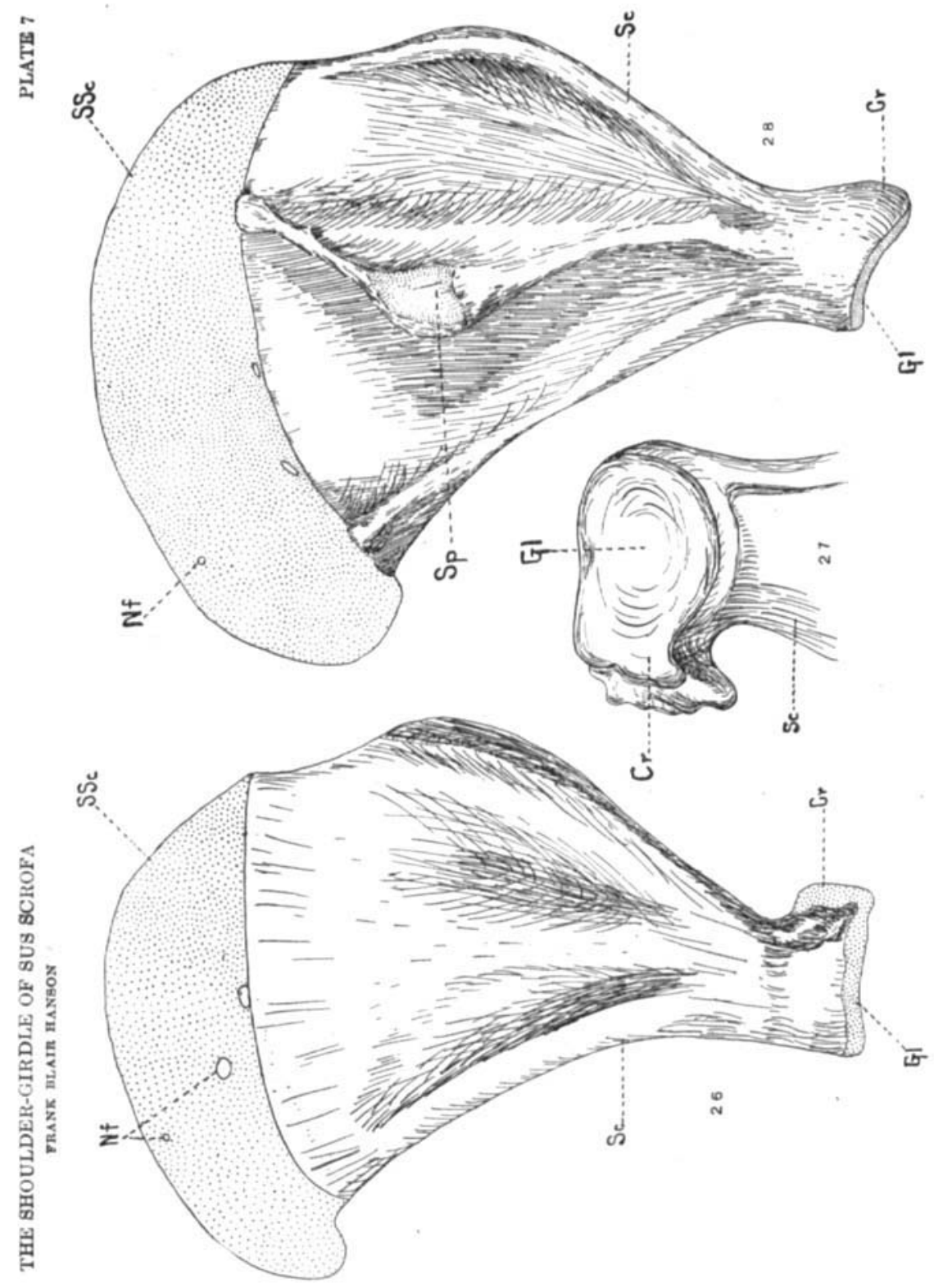

